\title{
OPEN Interactions of boron released from surface pre-reacted glass ionomer with enamel/dentin and its effect on $\mathrm{pH}$
}

\author{
Noriko Hiraishi ${ }^{1 凶}$, Mahmoud Sayed ${ }^{1}$, Robert Hill ${ }^{2}$, Junji Tagami $^{1}$ \& Fumiaki Hayashi ${ }^{3}$
}

This study investigated the interaction of borate ions released from surface pre-reacted glass ionomer (S-PRG) fillers with the biological apatites of enamel and dentin using solid-state (SS) magic-angle spinning nuclear magnetic resonance (MAS-NMR) spectroscopy analysis. We further evaluated the effect of borate ions on the $\mathrm{pH}$ change. Bovine enamel and dentin powder were submerged in S-PRG eluate (with borate ion concentration of $100 \mathrm{mM}$ ) for $3 \mathrm{~h}$, then washed with deionized water (DW). The dried enamel and dentin specimens were used for ${ }^{11}$ B SS-NMR and Fourier transform infrared spectroscopy (FT-IR) analysis. Enamel and dentin blocks were treated with three solutions: DW (control), S-PRG eluent and borate solution $(100 \mathrm{mM})$. The treated samples were submerged in the demineralization solution and the $\mathrm{pH}$ was measured using a $\mathrm{pH}$ meter daily for 6 days. The surfaces of the enamel and dentin blocks were then observed using field emission scanning electron microscopy (FE-SEM). SS-NMR analysis revealed the presence of adsorbed borate ions in the enamel and dentin samples in a tetra-coordinated form. The $\mathrm{pH}$ results demonstrated an increase in $\mathrm{pH}$ values in the S-PRG and borate groups. SEM images showed that the surfaces of the control group were demineralized, whereas the surfaces of the S-PRG and borate groups were intact. These results concluded that borate ions could be adsorbed to enamel and dentin in the tetra-coordinated form. Borate ions possess a buffer capacity which may help to protect the tooth structure against acid attacks and promote remineralization.

Despite the availability of numerous fluoride interventions, dental caries remains a common chronic disease with a global prevalence of $35 \%{ }^{1}$. Therefore, researchers have been investigating other strategies which work synergistically with or better than fluoride to reduce the risk of dental caries ${ }^{2}$.

Borate-based bioactive glasses are highly biocompatible materials with a wide variety of uses in medical and dental fields. Borate bioactive glasses are widely known to have various abilities, such as supporting the growth of bone cells ${ }^{3}$ and promoting the formation of hydroxyapatite $(\mathrm{HAp})^{4}$, as well as strongly bonding to hard and soft tissues $^{5}$. Bioactive glasses have numerous biomedical applications, including the repair of bone defects, scaffolds for bone and tooth tissue engineering, and teeth remineralization ${ }^{6}$.

Among the innovations which promote the concept of preventive and minimal invasive management of dental caries is the three-layer bioactive, Surface Pre-Reacted Glass ionomer filler (S-PRG) ${ }^{7}$. S-PRG filler is a unique particle which has been developed with the pre-reacted glass-ionomer technology to impart bioactive functions to restorative materials ${ }^{8}$. The pre-reacted glass-ionomer phase on the surface of the glass core allows S-PRG filler to release and recharge fluoride ions ${ }^{9}$. Moreover, the S-PRG filler has a unique characteristic of releasing other ions, such as aluminum $\left(\mathrm{Al}^{3+}\right)$, borate $\left(\mathrm{BO}_{3}{ }^{3-}\right)$, sodium $\left(\mathrm{Na}^{+}\right)$, silicate $\left(\mathrm{SiO}_{4}{ }^{4-}\right)$, and strontium $\left(\mathrm{Sr}^{2+}\right)$ ions, since a fluoro-boro-alumino-silicate glass is used as the glass core ${ }^{10,11}$.

Studies have reported that various bioactive effects are associated with the ions which are released from $S-P R G$, including antibacterial effects ${ }^{12}$, prevention of demineralization ${ }^{13}$, and enhancement of remineralization ${ }^{14}$. $\mathrm{BO}_{3}{ }^{3-}$ ion is well known for its antibacterial effect ${ }^{15}$. In addition, borate ions have biological effects, such as promoting bone formation and increasing HAp formation ${ }^{4,16}$.

\footnotetext{
${ }^{1}$ Cariology and Operative Dentistry, Graduate School of Medical and Dental Sciences, Tokyo Medical and Dental University, 1-5-45, Yushima, Bunkyo-ku, Tokyo 113-8549, Japan. ${ }^{2}$ Dental Physical Sciences, Barts and the London School of Medicine and Dentistry, Institute of Dentistry, Queen Mary University of London, London, UK. ${ }^{3}$ Advanced NMR Application and Platform Team, NMR Research and Collaboration Group, NMR Science and Development Division, RIKEN SPring-8 Center, Hyogo, Japan. ${ }^{\bowtie}$ email: hiraope@tmd.ac.jp
} 


\begin{tabular}{|l|c|c|l|l|l|l|}
\hline $\mathbf{p H} 7$ & $\mathbf{A l}^{3+}$ & $\mathbf{B O}_{3}{ }^{3-}$ & $\mathbf{N a}^{+}$ & $\mathbf{S i O}_{4}{ }^{4-}$ & $\mathbf{S r}^{2+}$ & $\mathbf{F}^{-}$ \\
\hline Ion concentration in ppm & 18.4 & 1368.4 & 477.7 & 8.4 & 167.1 & 127.5 \\
\hline Ion concentration in mM & 0.68 & 126.59 & 20.78 & 0.30 & 1.91 & 6.71 \\
\hline
\end{tabular}

Table 1. Different ions concentration in the S-PRG eluate.

Previous studies investigated the incorporation of ions quantitatively, which were released from S-PRG fillers into the tooth structure, using electron probe micro analysis (EPMA $)^{17}$, particle-induced X-ray $(\gamma$-ray) emission (PIXE/PIGE) ${ }^{18}$ and inductively coupled plasma atomic emission spectroscopy (ICP-AES) ${ }^{19}$. However, the chemical state and reactions of borate ion with the biological HAp of tooth structure or its effects on $\mathrm{pH}$ were not discussed earlier.

NMR can provide information at the atomic level about the structure and crystallinity for any material ${ }^{20} \cdot{ }^{11} \mathrm{~B}$ solid-state NMR is helpful to characterize of boron-containing compounds and can detect all structural forms of boron which exist with any compound ${ }^{21}$.

This study aimed to investigate the chemical interaction outcome of borate ions released from S-PRG fillers with the biological apatites of enamel and dentin using solid-state MAS-NMR spectroscopy analysis. Furthermore, we evaluated the effect of borate ions on the change of $\mathrm{pH}$ and observed the changes in the surface topography using FE-SEM.

\section{Materials and methods}

This study protocol was approved by the ethics committee of Tokyo Medical and Dental University under identification code "D2016-090". All methods in this study were performed following the relevant guidelines and regulations.

Pulverized dentin $(0.84 \mathrm{~g})$ and enamel $(0.6 \mathrm{~g})$ powder with particle size $50-75 \mu \mathrm{m}$ were obtained from the crowns of bovine incisor teeth. The crowns of the teeth were sliced into $1 \mathrm{~mm}$ thick sections, after which the enamel and dentin portion were carefully separated. The separated enamel and dentin sections were immersed in liquid nitrogen and finely ground to a homogenous powder in a mortar and sieved to $50 \sim 75 \mu \mathrm{m}$. Moreover, enamel and dentin blocks $(5 \times 5 \times 1 \mathrm{~mm})$ obtained from bovine incisor teeth were used in this study.

S-PRG eluate preparation. S-PRG saturated eluate was provided by Shofu Inc, Kyoto, Japan. To simulate the ion release from S-PRG fillers into the water medium, S-PRG saturated eluate was prepared by adding $1 \mathrm{~kg}$ of S-PRG fillers to $1 \mathrm{~L}$ of deionized water in a tumbler mixer at $23{ }^{\circ} \mathrm{C}$ for $24 \mathrm{~h}$ to become supernatant. Henceforth, the mixture was filtered through $0.45 \mu \mathrm{m}$ membrane pore filter. This eluate was measured by Inductively Coupled Plasma to report the ion concentration, as shown in Table 1.

NMR specimen preparation and characterization of NMR spectra. The S-PRG saturated eluate was diluted by DW to be $100 \mathrm{mM} \mathrm{BO}_{3}{ }^{3-}$. This solution was used hereafter as the S-PRG eluate. Each of the dentin $(0.28 \mathrm{~g})$, enamel $(0.2 \mathrm{~g})$ powder specimens $(\mathrm{n}=2)$ were submerged in the S-PRG eluate $(50 \mathrm{~mL})(\mathrm{pH} 7)$ for $3 \mathrm{~h}$ at $37^{\circ} \mathrm{C}$. In each $50 \mathrm{~mL}$ eluate, the mass of dentin specimen was greater than that of enamel specimen to consider the lower mineral percentage of dentin, which was $70 \%$ by weight compared to the enamel which has a mineral percentage of $95 \%^{22}$. Thereafter, the specimens were washed three times using $50 \mathrm{~mL} \mathrm{DW}$. After washing, the treated powder was dried up at room temperature in an ambient atmosphere. Synthetic nanocrystalline hydroxyapatite (nano-HAp) was obtained by the wet chemical technique using Habraken et al. methodology ${ }^{23}$ as follows: the reaction was done in a Tris-buffered saline (TBS) solution containing a $50 \mathrm{mM}$ Trizma-base and $150 \mathrm{mM}$ sodium chloride $(\mathrm{NaCl})$ in $\mathrm{DW}$ and the solution was set at $\mathrm{pH} 7.40$. The apatite precipitation was accomplished by incubating $5.88 \mathrm{mM} \mathrm{CaCl}_{2}$ with $4.12 \mathrm{mM} \mathrm{K}_{2} \mathrm{HPO}_{4}$ in TBS at $37^{\circ} \mathrm{C}$ for $24 \mathrm{~h}$. The specimens were then treated with S-PRG eluate in the same manner for NMR sample. This synthetic apatite served as a comparison with natural biological apatites such as dentin and enamel.

The dehydrated specimens were packed in a $3.2 \mathrm{~mm}$ zirconia dioxide rotor for the solid-state NMR measurements. The magic-angle spinning (MAS) frequency was $15 \mathrm{kHz}$. The ${ }^{11} \mathrm{~B}$ MAS NMR spectra were acquired in a single-pulse experiment of a $30 \mathrm{~s}$ recycle duration using JEOL (ECAII spectrometer $700 \mathrm{MHz}$ ). The spectra were acquired for enamel, dentin, nano-HAp and S-PRG fillers with scan accumulation of 256, 160, 868 and 32 scans, respectively. The NMR scans were different between the used substrates as the spectra were acquired with an accumulation between 32 and 868 scans depending on the boron level. The ${ }^{11} \mathrm{~B}$ NMR spectrum of S-PRG filler was taken to identify the boron coordination as the composition. The S-PRG eluate was also examined to confirm the complexation behavior of borate in aqueous solution. All the data processing was performed using Delta 5.1.3 NMR Software (JEOL, Tokyo, Japan).

Fourier transform infrared spectroscopy (FTIR). The dentin $(0.28 \mathrm{~g})$ and enamel ( $0.2 \mathrm{~g})$ powder specimens were prepared in the same method as NMR test. The infrared spectra of the dehydrated specimens in addition to S-PRG fillers were measured by FTIR spectroscopy. Approximately $5 \mathrm{mg}$ of the reacted materials were pressed in a $\mathrm{KBr}$ plastic pellet for $1 \mathrm{~min}$ at $700 \mathrm{MPa}$ to form a translucent disc for FTIR measurements. The adsorption spectra were measured from 500 to $4000 \mathrm{~cm}^{-1}$ with a resolution $4 \mathrm{~cm}^{-1}$ using IRT-5200 FTIR spectrometer (ATR pro one, Diamond prisma, JASCO, Tokyo, Japan). The spectra recorded were the average of 32 scans. 


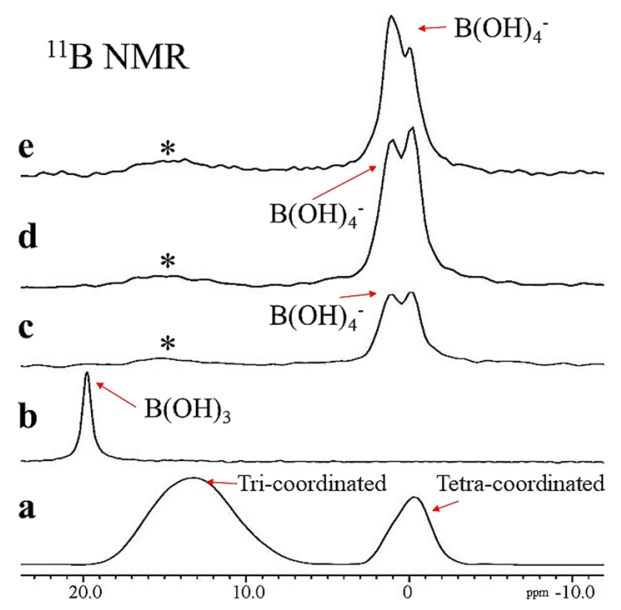

Figure 1. ${ }^{11}$ B MAS NMR spectra, (a) S-PRG fillers, (b) S-PRG eluate, (c) S-PRG treated dentin, (d) S-PRG treated enamel, (e) S-PRG treated nano-HAp.

pH measurement. Forty-eight (24 enamel and 24 dentin) specimens $(5 \times 5 \times 1 \mathrm{~mm})$ were used in this test. Enamel samples were obtained from the crown portion of bovine teeth, while dentin specimens were obtained from the cervical portion of bovine root. All specimens were polished till \#2000 using silicon carbide (SiC) paper under running water, then sonicated for $5 \mathrm{~min}$ in deionized water. A layer of clear acid-resistant nail varnish was applied on the specimen surfaces to expose a window of $5 \times 5 \mathrm{~mm}^{2}$. Specimens were divided into three groups $(\mathrm{n}=8)$ according to the tested solution applied: deionized water (control), S-PRG eluate and Borate solution (Wako pure, Osaka, Japan) (LOT\# PTF6991) with $\mathrm{pH} 7.4$ (adjusted by $\mathrm{NaOH}$ ) and borate ion concentration of $100 \mathrm{mM}$. The specimens were submerged in the testing solution $(30 \mathrm{~mL})$ for $3 \mathrm{~h}$. Each specimen was then immersed in $5 \mathrm{~mL}$ demineralizing solution $\left(50 \mathrm{mM}\right.$ acetic acid, $2.2 \mathrm{mM} \mathrm{CaCl}$ and $2.2 \mathrm{mM} \mathrm{KH}_{2} \mathrm{PO}_{4}, \mathrm{pH} 4.5$ adjusted by $\mathrm{NaOH})^{24}$ in a separate plastic chamber for 7 days at $37^{\circ} \mathrm{C}$. The $\mathrm{pH}$ was measured daily for 6 days using $\mathrm{pH}$ meter (F-52, Horiba ltd., Tokyo, Japan $)^{25}$.

SEM observation. After finishing $\mathrm{pH}$ measurement test, specimens were taken out of the demineralizing solution and washed with DW. After this, specimens were fixed using $2.5 \%$ glutaraldehyde for $2 \mathrm{~h}$ at $4{ }^{\circ} \mathrm{C}$ for primary fixation, followed with $0.1 \%$ osmium tetroxide solution for $2 \mathrm{~h}$ at $4{ }^{\circ} \mathrm{C}$ for secondary fixation then dehydrated in ascending concentrations of ethanol (50\%, 70\%, 80\%, 90\% and 95\% for 25 min each; then, twice in $100 \%$ for $25 \mathrm{~min}$ each) ${ }^{26}$. Specimens were then dried in a desiccator and finally sputter-coated with platinum/ gold coating. The surfaces were observed using a FE-SEM (FE-SEM, S-4500, Hitachi Ltd., Tokyo, Japan) with operating conditions of $5 \mathrm{kV}$.

Statistics. The number of specimens per group (n) was calculated using the sample size determination method for the two tailed test as follows: $\mathrm{n}=2\left(\mathrm{Z}_{\alpha / 2}+\mathrm{Z}_{\beta}\right)^{2} \times \mathrm{SD}^{2} / \Delta^{2}$. The significance level was set to $1 \%$ $\left(\mathrm{Z}_{\alpha / 2}=2.576\right)$ and the statistical power level to $90 \%\left(\mathrm{Z}_{\beta}=1.282\right)$. The difference between mean $\mathrm{pH}$ values obtained after 1 and 2 days $(\Delta \approx 0.1)$ and the standard deviation $(S D \approx 0.03)$ were obtained from a pilot study with five specimens per group. The sample size calculated using the aforementioned equation was 2.68 , however, the number of specimens per group was increased to eight to check the reliability of data. Data were analyzed for normality using the Kolmogorov-Smirnov, and Shapiro-Wilk tests. The $\mathrm{pH}$ data were analyzed using two-way repeated measures ANOVA followed by the Turkey-HSD post-hoc test. Significance was set at $p<0.05(\mathrm{n}=8$ for each group). Statistical analysis was performed using IBM SPSS (SPSS Inc., IBM Corporation, NY, USA) Statistics Version 23 for Windows.

\section{Results}

${ }^{11}$ B MAS-NMR spectra. In the S-PRG fillers specimen (Fig. 1a), two broad spectral peaks were identified at $13.2 \mathrm{ppm}$ and $-0.3 \mathrm{ppm}$ corresponding to tri-coordinated and tetra-coordinated borate ions, respectively ${ }^{27}$. A sharp spectral peak was identified at 20.0 ppm in the S-PRG eluate (Fig. 1b), which is related to aqueous $\mathrm{B}(\mathrm{OH})_{3}$. For the enamel, dentin, and nano-HAp powder treated with the S-PRG eluate for $3 \mathrm{~h}$, two dominant peaks, that is, the chemical shifts at $0.0 \mathrm{ppm}$ and $1.0 \mathrm{ppm}$ are attributed to tetra-coordinated borate ion in the form of $\mathrm{B}(\mathrm{OH})_{4}{ }^{-}$(Fig. 1c-e). The spectral peaks in dentin and nano-HAp specimens had a higher intensity than enamel specimens. The trace of tri-coordinated borate ion $\mathrm{B}(\mathrm{OH})_{3}$ was identified, ranging from 16 to 14 ppm, shown by asterisks shown in Fig. 1c-e.

FTIR spectra. FTIR spectra were collected for the tested specimens, which is shown in Fig. 2. Both the enamel powder treated with the S-PRG eluate for $3 \mathrm{~h}$ and untreated enamel (control), revealed three vibrational band peaks centered at 1032,603 , and $564 \mathrm{~cm}^{-1}$ corresponding to the phosphate group $\left(\mathrm{PO}_{4}{ }^{3-}\right)$ in the HAp. The dentin powder treated with the S-PRG eluate for $3 \mathrm{~h}$ and the untreated dentin (control) showed three major 


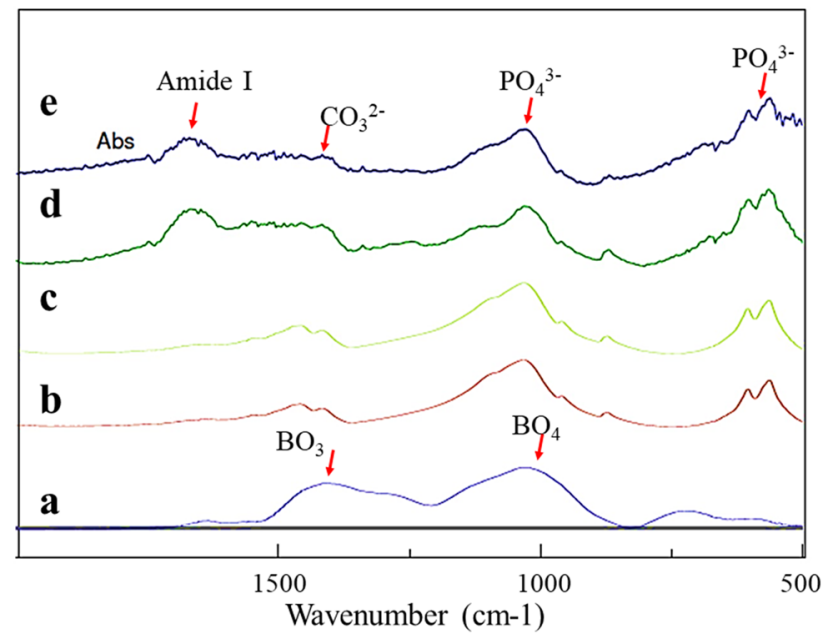

Figure 2. Representative FTIR spectra for the tested specimens, (a) S-PRG fillers, (b) untreated enamel (control), (c) S-PRG treated enamel, (d) untreated dentin (control), (e) S-PRG treated dentin. The peaks centered at 1067 and 1375 are corresponding to $\mathrm{BO}_{4}$ and $\mathrm{BO}_{3}$, respectively.

\begin{tabular}{|c|c|c|c|}
\hline & Control & Eluate & Borate \\
\hline \multicolumn{4}{|l|}{ (A) } \\
\hline Day 1 & $4.68 \pm 0.03^{\mathrm{aA}}$ & $5.55 \pm 0.02^{\mathrm{aB}}$ & $5.13 \pm 0.04^{\mathrm{aC}}$ \\
\hline Day 2 & $4.76 \pm 0.01^{\mathrm{bA}}$ & $5.63 \pm 0.01^{\mathrm{bB}}$ & $5.24 \pm 0.02^{\mathrm{bC}}$ \\
\hline Day 3 & $4.85 \pm 0.01^{\mathrm{cA}}$ & $5.66 \pm 0.02^{\mathrm{cB}}$ & $5.27 \pm 0.02^{\mathrm{cC}}$ \\
\hline Day 4 & $4.95 \pm 0.01^{\mathrm{dA}}$ & $5.72 \pm 0.01 \mathrm{~dB}$ & $5.32 \pm 0.01^{\mathrm{dC}}$ \\
\hline Day 5 & $5.03 \pm 0.06^{\mathrm{eA}}$ & $5.79 \pm 0.01^{\mathrm{eB}}$ & $5.35 \pm 0.01^{\mathrm{eC}}$ \\
\hline Day 6 & $5.18 \pm 0.03^{\mathrm{fA}}$ & $5.82 \pm 0.01^{\mathrm{eB}}$ & $5.38 \pm 0.02^{\mathrm{eC}}$ \\
\hline \multicolumn{4}{|l|}{ (B) } \\
\hline Day 1 & $4.66 \pm 0.03^{\mathrm{aA}}$ & $5.52 \pm 0.01^{\mathrm{aB}}$ & $5.12 \pm 0.05^{\mathrm{aC}}$ \\
\hline Day 2 & $4.75 \pm 0.01^{\mathrm{bA}}$ & $5.58 \pm 0.02^{\mathrm{bB}}$ & $5.19 \pm 0.02^{\mathrm{bC}}$ \\
\hline Day 3 & $4.84 \pm 0.04^{\mathrm{cA}}$ & $5.64 \pm 0.01^{\mathrm{cB}}$ & $5.26 \pm 0.01^{\mathrm{cC}}$ \\
\hline Day 4 & $4.92 \pm 0.01^{\mathrm{dA}}$ & $5.7 \pm 0.03 \mathrm{~dB}$ & $5.3 \pm 0.04^{\mathrm{cC}}$ \\
\hline Day 5 & $4.95 \pm 0.01^{\mathrm{dA}}$ & $5.75 \pm 0.05^{\mathrm{eB}}$ & $5.35 \pm 0.01^{\mathrm{dC}}$ \\
\hline Day 6 & $5.14 \pm 0.02^{\mathrm{eA}}$ & $5.8 \pm 0.01^{\mathrm{fB}}$ & $5.37 \pm 0.03^{\mathrm{dC}}$ \\
\hline
\end{tabular}

Table 2. Means and standard deviation for the $\mathrm{pH}$ values of the solutions containing the different tested groups (A) Dentin, (B) Enamel. Different superscript uppercase letters indicate significant difference within each row, and lowercase letters indicate significant difference within each column $(\mathrm{p}<0.05)$.

vibrational band peaks centered at 1032,603 , and $564 \mathrm{~cm}^{-1}$, again corresponding to the phosphate group $\left(\mathrm{PO}_{4}{ }^{3-}\right)$ in the hydroxyapatite. Other two vibrational band peaks centered at 1400 and 1450 related to carbonate groups $\left(\mathrm{CO}_{3}{ }^{2}\right)$ within the $\mathrm{HAp}^{28}$ and the Amide I band displayed at $1647 \mathrm{~cm}^{-1}$ for dentin samples. The FTIR spectra for the S-PRG fillers demonstrated two major vibrational band peaks centered at 1067 and 1375, corresponding to $\mathrm{BO}_{4}$ and $\mathrm{BO}_{3}$, respectively ${ }^{29}$. In the FTIR spectra for the treated enamel and dentin specimens, it was difficult to identify the $\mathrm{B}(\mathrm{OH})_{4}{ }^{-}$ions because their vibrational bands overlapped with those of phosphate ion $\left(\mathrm{PO}_{4}\right)$ located in the HAp crystals.

$\mathrm{pH}$ measurement. The $\mathrm{pH}$ value of the solution (Table 2), containing untreated dentin (control), gradually and slightly increased from $4.68( \pm 0.03)$ after 1 day to reach $5.18( \pm 0.03)$ after 6 days. In the case of the solution containing dentin treated with S-PRG eluate for $3 \mathrm{~h}$, the $\mathrm{pH}$ value showed a rapid increase to $5.54( \pm 0.02)$ after 1 day and a further increase to reach $5.82( \pm 0.01)$ after 6 days. For the solution containing dentin samples treated with borate solution for $3 \mathrm{~h}$, the $\mathrm{pH}$ value showed a slight rapid increase, reaching $5.13( \pm 0.04)$ after a day, followed by an increase reaching $5.38( \pm 0.02)$ after 6 days. The pH values of the S-PRG and borate groups were significantly higher than those of the control group at all time intervals with $\mathrm{p}<0.05$ (Fig. 3). The $\mathrm{pH}$ values of the solutions containing enamel samples showed the same pattern as the dentin samples, but with slight lower degree of increase; the solutions of the control group showed a gradual increase in the $\mathrm{pH}$ value, starting from $4.66( \pm 0.03)$ after a day and reaching $5.14( \pm 0.02)$ after 6 days. The S-PRG eluate group showed a rapid increase 
Dentin

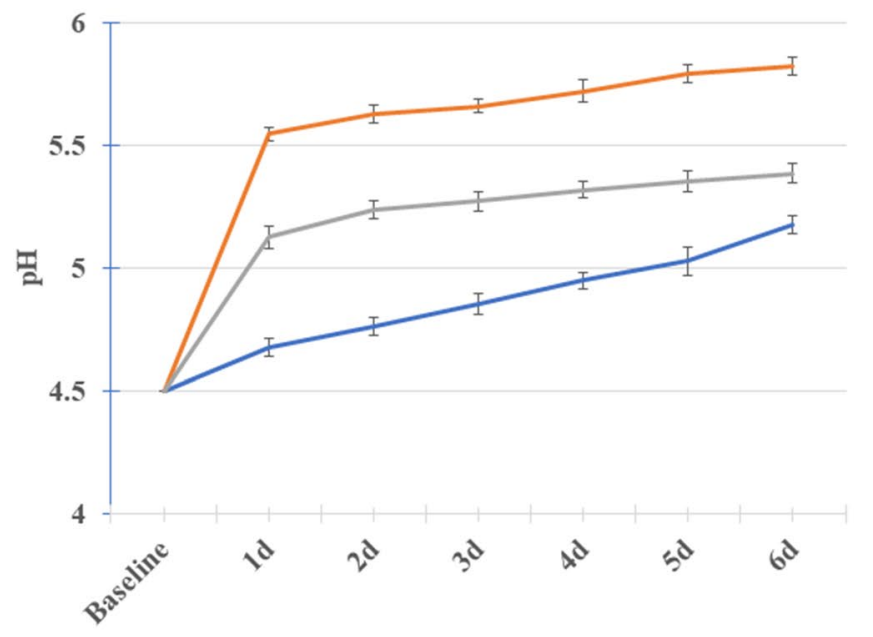

Time

—S-PRG Eluate (dentin)

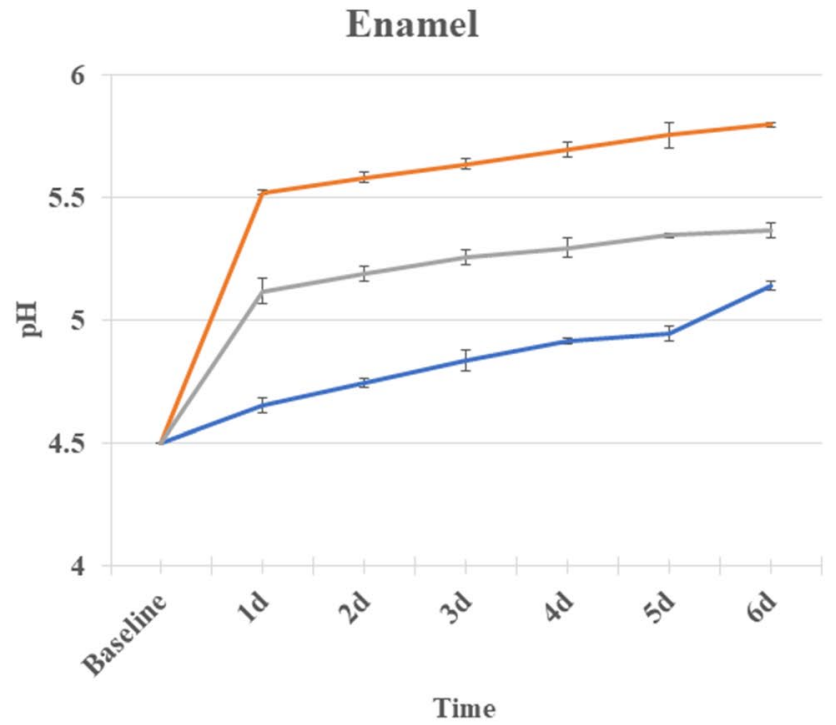

- Con trol (enam el)

- Borate (enam el)
—S-PRG Eluate (enam el)

Figure 3. The $\mathrm{pH}$ plotted against time showing the changes in the $\mathrm{pH}$ values for the different tested groups. Statistical analysis was performed using two-way repeated measures ANOVA.

in $\mathrm{pH}$ value reaching $5.52( \pm 0.01)$ after a day, followed by a slight gradual increase in $\mathrm{pH}$ value until it reached $5.80( \pm 0.01)$ after 6 days. The borate group solution showed a rapid increase in $\mathrm{pH}$ to $5.12( \pm 0.05)$ after a day, followed by a stable slight increase to $5.37( \pm 0.03)$ after 6 days. $\mathrm{pH}$ values of S-PRG eluate and borate group were significantly higher than those of the control group at all time intervals at $\mathrm{p}<0.05$ (Fig. 3).

FE-SEM observation. The FE-SEM images in the untreated dentin specimens (control) (Fig. 4a) revealed a demineralized dentin surface associated with exposure of dentin collagen. The images in the dentin specimens treated with the S-PRG eluate for $3 \mathrm{~h}$ (Fig. $4 \mathrm{~b}$ ) showed a slight demineralization of the peritubular dentin, but apparently an intact dentin surface. The dentin sample treated with the borate solution for $3 \mathrm{~h}$ (Fig. $4 \mathrm{c}$ ) showed the similar morphology as the eluate of S-PRG, but there was a trace of erosion in the intertubular dentin in this sample.

All enamel specimens did not show any prismatic pattern (Fig. $4 \mathrm{~d}-\mathrm{f}$ ), indicating that the surfaces were not demineralized (Supplemental figure S1). However, in the control enamel, an array of enamel crystals was observed in the area between the prisms in the high magnification $(30,000 \times)$ image (Fig. 4g). On the other hand, the S-PRG eluate group (Fig. 4e,i) and the borate group (Fig. 4f,h) showed an intact enamel surface and less exposure of enamel crystals.

\section{Discussion}

Solid-state (SS) MAS-NMR spectroscopy revealed the interaction of borate ions released from S-PRG fillers with the biological apatites of enamel and dentin. The results showed that when the S-PRG eluate interacted with enamel and dentin, tetra-coordinated borate ions $\mathrm{B}(\mathrm{OH})_{4}{ }^{-}$were adsorbed on HAp, whearas the tri-coordinated borate $\mathrm{B}(\mathrm{OH})_{3}$ was not located at any site in the enamel or dentin substrate.

The behavior of borate ions released from S-PRG was not completely understood. A previous ICP-AES analysis revealed the effective incorporation of borate ions into the human dental enamel through the simultaneous integration of anions and cations under balanced-charge circumstances ${ }^{19}$. However, this study did not determine the specific borate species incorporated.

We performed the ${ }^{11} \mathrm{~B}$ NMR analysis on enamel and dentin, providing evidence of the coordination mode of borate ion. The difference in NMR spectra between the $\mathrm{BO}_{3}$ unit and $\mathrm{BO}_{4}$ unit is due to the structural differences between both units. The $\mathrm{BO}_{3}$ unit consists of a planer structure, in which the boron lies at the center of an oxygen triangle (trigonal). Therefore, the nuclear quadrupole moment of ${ }^{11} \mathrm{~B}$ in $\mathrm{BO}_{3}$ unit becomes large. Alternatively, in the $\mathrm{BO}_{4}$ unit, the boron is located at the center of an oxygen tetrahedron (tetrahedral). The quadrupole moment becomes small due to the spherical symmetry around the ${ }^{11} \mathrm{~B}$, hence the a sharper resonance line is observed for the transition. These two specific ${ }^{11} \mathrm{~B}$ adsorptions from $\mathrm{BO}_{3}$ and $\mathrm{BO}_{4}$ can easily be separated, enabling one to obtain the fraction of each species ${ }^{30}$.

Boric acid is a very weak acid with a pKa value of 9.24. This acid accepts a pair of electrons from a hydroxyl ion to form a borate ion, acting as a Lewis acid. The dominant forms of boron atoms in aqueous systems exist as either non-ionized tri-coordinated $\mathrm{B}(\mathrm{OH})_{3}$ or ionized tetra-coordinated $\mathrm{B}(\mathrm{OH})_{4}{ }^{-29,31}$, exchanging with each other in the state of equilibrium within the aqueous media ${ }^{32,33}$ as below: 

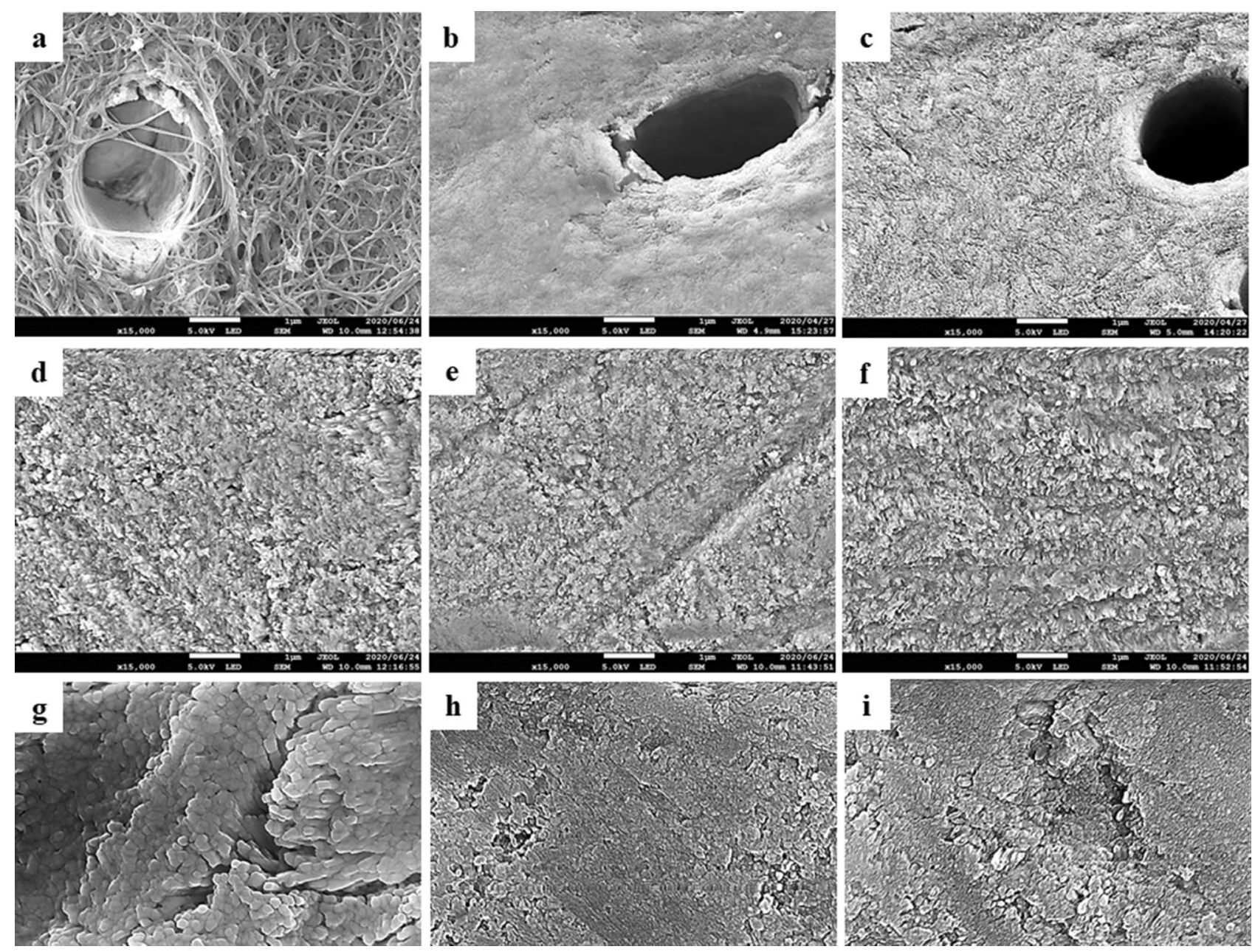

Figure 4. SEM images for the dentin and enamel surfaces at $\times 15,000$ magnification (scale bar $1 \mu \mathrm{m}),(\mathbf{a})$ control "dentin", (b) S-PRG eluate "dentin", (c) Borate "dentin", (d) control "enamel”, (e) S-PRG eluate "enamel", (f) Borate "enamel", (g) control "enamel" at $\times 30,000$ magnification while arrows refer to the interprismatic area (scale bar $0.1 \mu \mathrm{m}$ ), (h) S-PRG eluate "enamel" at $\times 30,000$ magnification (scale bar $0.1 \mu \mathrm{m})$, (i) Borate "enamel" at $\times 30,000$ magnification (scale bar $0.1 \mu \mathrm{m}$ ).

$$
\mathrm{B}(\mathrm{OH})_{3}+\mathrm{H}_{2} \mathrm{O} \rightleftarrows \mathrm{B}(\mathrm{OH})_{4}^{-}+\mathrm{H}^{+} \mathrm{pKa}=9.24
$$

Thus, the status of borate ions is affected by the $\mathrm{pH}$ value of the solution ${ }^{31}$. Since the eluate of S-PRG was at $\mathrm{pH}$ 7, which was lower than the $\mathrm{pKa}$ value, $\mathrm{B}(\mathrm{OH})_{3}$ should have been predominant and the eluate should have contained only trace amounts of ionized $\mathrm{B}(\mathrm{OH})_{4}$. This was confirmed by the NMR results, which showed that nonionized $\mathrm{B}(\mathrm{OH})_{3}$ was predominant in the eluate (Fig. $1 \mathrm{~b}$ ), and the signal of ionized $\mathrm{B}(\mathrm{OH})_{4}$ was rarely detected.

However, the $\mathrm{B}(\mathrm{OH})_{4}{ }^{-}$was detected in the enamel and dentin samples treated with the eluate and the nanoHAp "pure inorganic apatite" specimens. This finding might be related to the electrostatic adsorption of the negatively charged $\mathrm{B}(\mathrm{OH})_{4}{ }^{-}$ions occurring on the sites of positively charged calcium ions in the enamel, dentin, and nano-HAp substrates ${ }^{34}$. The continuous adsorption of the $\mathrm{B}(\mathrm{OH})_{4}{ }^{-}$ions to the positively charged sites would shift the equilibrium between $\mathrm{B}(\mathrm{OH})_{3}$ and $\mathrm{B}(\mathrm{OH})_{4}{ }^{-}$ions to the right side of the Eq. (1), favoring the formation of more $\mathrm{B}(\mathrm{OH})_{4}{ }^{-}$ions. Thus, the consumption of $\mathrm{B}(\mathrm{OH})_{4}{ }^{-}$ions due to the electrostatic adsorption on enamel and dentin surfaces produced additional $\mathrm{B}(\mathrm{OH})_{4}{ }^{-}$ions. This electrostatic adsorption of $\mathrm{B}(\mathrm{OH})_{4}{ }^{-}$ions might continue until the surface of enamel, dentin and nano-HAp substrates were electrostatically neutralized.

The electrostatic adsorption site of the $\mathrm{B}(\mathrm{OH})_{4}{ }^{-}$ions with HAp can be possible because of the charge distribution of the HAp hexagonal structure. This structure of the HAp crystal possesses two planes. a(b)-plane mainly presents positively-charged calcium ions, while c-plane mainly presents negatively-charged phosphate ions and hydroxyl groups ${ }^{35}$. In the case of enamel, the presence of amelogenin "enamel matrix protein" adjacent to the $\mathrm{a}$ - and b-surfaces of the HAp crystallites favors the crystallite growth in the c-axis direction resulting in thin and long crystals ${ }^{36}$. Whereas in the dentin HAp case scenario, the arrangement of nano-crystalline clusters of amorphous calcium phosphate support the crystallite growth and elongation in the c-axis direction, leading to an increase in the a(b)-plane ${ }^{37}$. Consequently, this may render the HAp to become more positively charged. Moreover, the incorporation of the $\mathrm{CO}_{3}{ }^{2-}$ ions in the hexagonal apatite structure in dentin induces the 
increase of the positively-charged calcium-rich a(b)-planes of the HAp crystal leading to more adsorption of the $\mathrm{B}(\mathrm{OH})_{4}{ }^{-}$ions ${ }^{35}$. Therefore, the difference in crystallinity and composition between dentin and enamel may be related to the reactivity of borate ions to dentin and enamel. In fact, the spectral peak of dentin was more intense than that of enamel, indicating a higher concentration of borate ions in dentin. This suggests that dentin is more reactive than enamel to borate ions.

Regarding the FTIR spectra (Fig. 2), the relationship between the infrared spectra and the molecular configuration for the boric acid $\left(\mathrm{BO}_{3}\right)$ and borate ion $\left(\mathrm{B}(\mathrm{OH})_{4}{ }^{-}\right)$was clarified by Nakamoto et al. using symmetry rules, defining boric acid as YX3 and borate ion as $\mathrm{YX}^{38}$. Considering this relation, boric acid (YX3), with its asymmetric B-O stretching (v3), should have one IR active peak $\left(1500-1300 \mathrm{~cm}^{-1}\right)$, while borate ion (YX4) has one broad $\mathrm{v} 3$ asymmetric stretching band with an active IR peak around $950 \mathrm{~cm}^{-138}$. The difficulty in identifying $\mathrm{B}(\mathrm{OH})_{4}{ }^{-}$ions in the enamel and dentin specimens might be attributed to the overlap between the $\mathrm{PO}_{4}$ and $\mathrm{BO}_{4}$ peaks. It is, however, suggested that trigonal boron might not present in the enamel and dentin specimens. Meanwhile, $\mathrm{BO}_{3}$ peak was only found in the S-PRG filler, confirming the NMR results.

In the $\mathrm{pH}$ measurements (Fig. 3), the rapid increase in the $\mathrm{pH}$ measurement values within the first day in the S-PRG and borate groups might be related to the release of ions in large quantities during this short period compared with the other periods ${ }^{25}$. The control groups (enamel and dentin), buffered the demineralizing solution as a result of ionic dissolution during enamel and dentin demineralization and subsequent release of $\mathrm{Ca}_{2}{ }^{+}$, $\mathrm{OH}^{-}$and $\mathrm{PO}_{4}{ }^{3+}$, resulting in neutralization of the $\mathrm{pH}^{25}$. Besides this original buffering effect of HAp, the S-PRG treated groups possessed additional buffer capacity as the adsorbed tetrahedral borate ions on the surface of the treated HAp are more susceptible to be converted to trihedral in acidic (protonated) media rather than in neutral or basic media ${ }^{39}$. When the conversion of tetrahedral boron to trigonal boron occurred, acid (hydrogen ions) was consumed, which subsequently increased the $\mathrm{pH}^{39}$. This ability to consume hydrogen ions $\left(\mathrm{H}^{+}\right)$gives the borate solution its buffer capacity ${ }^{40}$, as shown in Eq. (1).

Besides the borate ion, it was suggested that the buffering capacity of S-PRG also resulted from the release of ions into a solution such as $\mathrm{Sr}^{2+}$ and $\mathrm{Na}^{+}$by an ion exchange process for $\mathrm{H}^{+}$ions and the formation of alkaline compounds, such as $\mathrm{NaOH}$ and $\mathrm{Sr}(\mathrm{OH})_{2}^{4}$. In addition, the release of fluoride ions can exchange with the $\mathrm{H}^{+}$ ions in the solution, rendering it more alkaline. Also, fluoride ions can induce the precipitation of apatites from acidic precursors, such as amorphous calcium phosphate and octacalcium phosphate ${ }^{41}$. Thus, the multiple ions are involved in the buffer capacity of S-PRG. For these reasons, the eluate of S-PRG showed a greater buffering effect than the borate solution.

The buffer capacity of the S-PRG and borate solutions were confirmed by FE-SEM images (Fig. 4) which revealed a more intact dentin surface than the demineralized dentin surface in the control group that showed an exposed collagen matrix. The slight morphological difference between the S-PRG and the borate samples might be related to the higher $\mathrm{pH}$ value for the S-PRG sample than the borate sample.

Prisms typically appear on the demineralized enamel surface as observed by SEM, while prisms do not appear on intact ground enamel ${ }^{42}$. However, the in current study, no remarkable prismatic pattern was observed for all enamel samples. This might be related to the fact that the surface was moderately demineralized due to the use of pH 4.5 solution for 6 days without replacement. When observed at high magnification $(30,000 \times)$, the untreated control group showed signs of demineralization with an array of enamel crystals (Fig. 4g), confirming the morphological differences from the treated groups. The difference in the SEM images was consistent with that in the increase in $\mathrm{pH}$, showing a slower $\mathrm{pH}$ increase for the control than the treated groups.

In the present investigation, it was found that the S-PRG eluate mainly contained aqueous $\mathrm{B}(\mathrm{OH})_{3}$, but negatively charged $\mathrm{B}(\mathrm{OH})_{4}{ }^{-}$ions were adsorbed on the surface of enamel and dentin. The adsorbed $\mathrm{B}(\mathrm{OH})_{4}{ }^{-}$ions might be used to neutralize acidic conditions when $\mathrm{B}(\mathrm{OH})_{3}$ was converted to $\mathrm{B}(\mathrm{OH})_{4}{ }^{-}$. Further studies are needed to focus on the quantitative information on the degree of dentin demineralization.

\section{Conclusion}

Borate ions adsorbe to the surface of enamel and dentin powder in the tetra-coordinated form. The adsorbed $\mathrm{B}(\mathrm{OH})_{4}{ }^{-}$ions possess a buffer capacity when $\mathrm{B}(\mathrm{OH})_{3}$ converted to $\mathrm{B}(\mathrm{OH})_{4}^{-}$, which helps to protect the tooth structure against acid attacks.

Received: 11 November 2020; Accepted: 19 July 2021

Published online: 03 August 2021

\section{References}

1. Kassebaum, N. J. et al. Global burden of untreated caries: A systematic review and metaregression. J. Dent. Res. 94, 650-658 (2015).

2. Rethman, M. P. et al. Nonfluoride caries-preventive agents: Executive summary of evidence-based clinical recommendations. J. Am. Dent. Assoc. 142, 1065-1071 (2011).

3. Matsuda, T. \& Davies, J. E. The in vitro response of osteoblasts to bioactive glass. Biomaterials 8, 275-284 (1987).

4. Brown, R. F. et al. Effect of borate glass composition on its conversion to hydroxyapatite and on the proliferation of MC3T3-E1 cells. J. Biomed. Mater. Res. Part A 88, 392-400 (2009).

5. Hench, L. L. \& Paschall, H. A. Direct chemical bond of bioactive glass-ceramic materials to bone and muscle. J. Biomed. Mater. Res. 7, 25-42 (1973).

6. Gu, Y. et al. Kinetics and mechanisms of converting bioactive borate glasses to hydroxyapatite in aqueous phosphate solution. J. Mater. Sci. 46, 47-54 (2011).

7. Amaechi, B. T. et al. Effectiveness of S-PRG filler-containing toothpaste in inhibiting demineralization of human tooth surface. Open Dent. J. 12, 811 (2018).

8. Imazato, S., Ma, S., Chen, J. \& Xu, H. H. Therapeutic polymers for dental adhesives: Loading resins with bio-active components. Dent. Mater. 30, 97-104 (2014). 
9. Han, L. et al. Effect of fluoride mouth rinse on fluoride releasing and recharging from aesthetic dental materials. Dent. Mater. J. 21, 285-295 (2002).

10. Nomura, R., Morita, Y., Matayoshi, S. \& Nakano, K. Inhibitory effect of surface pre-reacted glass-ionomer (S-PRG) eluate against adhesion and colonization by Streptococcus mutans. Sci. Rep. 8, 1-18 (2018).

11. Lee, M. et al. Bioactive resin-based composite with surface pre-reacted glass-ionomer filler and zwitterionic material to prevent the formation of multi-species biofilm. Dent. Mater. 35, 1331-1341 (2019).

12. Hotta, M., Morikawa, T., Tamura, D. \& Kusakabe, S. Adherence of Streptococcus sanguinis and Streptococcus mutans to salivacoated S-PRG resin blocks. Dent. Mater. J. 33, 261-267 (2014).

13. Ma, S. et al. Effects of a coating resin containing S-PRG filler to prevent demineralization of root surfaces. Dent. Mater. J. 31, 909-915 (2012).

14. Iijima, M. et al. Effects of immersion in solution of an experimental toothpaste containing S-PRG filler on like-remineralizing ability of etched enamel. Dent. Mater. J. 33, 430-436 (2014).

15. Yilmaz, M. T. Minimum inhibitory and minimum bactericidal concentrations of boron compounds against several bacterial strains. Turk. J. Med. Sci. 42, 1423-1429 (2012).

16. Kitagawa, H. et al. Inhibitory effect of resin composite containing S-PRG filler on Streptococcus mutans glucose metabolism. J. Dent. 70, 92-96 (2018).

17. Han, L. \& Okiji, T. Evaluation of the ions release/incorporation of the prototype S-PRG filler-containing endodontic sealer. Dent. Mater. J. 30, 898-903 (2011).

18. Funato, Y. et al. A new technique for analyzing trace element uptake by human enamel. Dent. Mater. J. 34, 240-245 (2015).

19. Ogawa, A., Wada, T., Mori, Y. \& Uo, M. Time dependence of multi-ion absorption into human enamel from surface prereacted glass-ionomer (S-PRG) filler eluate. Dent. Mater. J. 38, 707-712 (2019).

20. Gerothanassis, I. P., Troganis, A., Exarchou, V. \& Barbarossou, K. Nuclear magnetic resonance (NMR) spectroscopy: Basic principles and phenomena, and their applications to chemistry, biology and medicine. Chem. Educ. Res. Pract. 3, 229-252 (2002).

21. Murakami, M. et al. 10B/11B 1D/2D solid-state high-resolution NMR studies on boron-doped diamond. Diam. Relat. Mater. 18, 1267-1273 (2009).

22. Goldberg, M., Kulkarni, A. B., Young, M. \& Boskey, A. Dentin: Structure, composition and mineralization. Front. Biosci. (Elite Ed) 3, 711-735 (2011).

23. Habraken, W. J. et al. Ion-association complexes unite classical and non-classical theories for the biomimetic nucleation of calcium phosphate. Nat. Commun. 4, 1-12 (2013).

24. Sayed, M. et al. Effect of silver-containing agents on the ultra-structural morphology of dentinal collagen. Dent. Mater. 36, 936-944 (2020).

25. Kaga, M. et al. Inhibition of enamel demineralization by buffering effect of S-PRG filler-containing dental sealant. Eur. J. Oral Sci. 122, 78-83 (2014).

26. Sayed, M. et al. Morphological and elemental analysis of silver penetration into sound/demineralized dentin after SDF application. Dent. Mater. 35, 1718-1727 (2019).

27. Covington, A. K. \& Newman, K. E. Base dissociation constant of the borate ion from 11B chemical shifts. J. Inorg. Nucl. Chem. 35 , 3257-3262 (1973).

28. Han, X. \& Day, D. Reaction of sodium calcium borate glasses to form hydroxyapatite. J. Mater. Sci. Mater. Med. 18, 1837-1847 (2007).

29. Ardelean, I., Toderas, M. \& Paşcuţa, P. Structural study of the $\mathrm{Fe}_{2} \mathrm{O}_{3}-\mathrm{B}_{2} \mathrm{O}_{3}-\mathrm{BaO}$ glass system by FTIR spectroscopy. Mod. Phys. Lett. B 17, 1175-1179 (2003).

30. Du, W., Kuraoka, K., Akai, T. \& Yazawa, T. Study of kinetics of the phase separation in sodium borate glasses. J. Mater. Sci. 35, 3913-3921 (2000).

31. Ramkumar, J. et al. Boroaluminosilicate glasses as ion exchange materials. J. Non-Cryst. Solids 356, 2813-2819 (2010).

32. Taler, G., Schejter, A. \& Navon, G. 1H and 11B NMR evidence for specific binding of borate ion to cytochrome c. Inorg. Chim. Acta 273, 388-392 (1998).

33. Kim, D. H., Marbois, B. N., Faull, K. F. \& Eckhert, C. D. Esterification of borate with NAD+ and NADH as studied by electrospray ionization mass spectrometry and 11B NMR spectroscopy. J. Mass Spectrom. 38, 632-640 (2003).

34. Skwarek, E., Janusz, W. \& Sternik, D. The influence of the hydroxyapatite synthesis method on the electrochemical, surface and adsorption properties of hydroxyapatite. Adsorpt. Sci. Technol. 35, 507-518 (2017).

35. Aizawa, M., Matsuura, T. \& Zhuang, Z. Syntheses of single-crystal apatite particles with preferred orientation to the a-and c-axes as models of hard tissue and their applications. Biol. Pharm. Bull. 36, 1654-1661 (2013).

36. He, L. H. \& Swain, M. V. Understanding the mechanical behaviour of human enamel from its structural and compositional characteristics. J. Mech. Behav. Biomed. Mater. 1, 18-29 (2008).

37. He, G., Dahl, T., Veis, A. \& George, A. Nucleation of apatite crystals in vitro by self-assembled dentin matrix protein 1. Nat. Mater. 2, 552-558 (2003).

38. Nakamoto, K. Infrared and Raman Spectra of Inorganic and Organometallic Compounds (Wiley, 1986).

39. Geneste, G., Bouyer, F. \& Gin, S. Hydrogen-sodium interdiffusion in borosilicate glasses investigated from first principles. J. Non Cryst. Solids 352, 3147-3152 (2006).

40. Ito, S. et al. Effects of surface pre-reacted glass-ionomer fillers on mineral induction by phosphoprotein. J. Dent. 39, 72-79 (2011).

41. Robinson, C. et al. The effect of fluoride on the developing tooth. Caries Res. 38, 268-276 (2004).

42. Kanemura, N., Sano, H. \& Tagami, J. Tensile bond strength to and SEM evaluation of ground and intact enamel surfaces. J. Dent. 27, 523-530 (1999).

\section{Acknowledgements}

This work was conducted under the Joint Research Project between Department of Cariology and Operative Dentistry, Tokyo Medical and Dental University, and NMR Science and Development Division, RIKEN SPring-8 Center. Partly supported by a Grant from the Japan Society for the Promotion of Science (20K09972). The authors declare no competing interest. All authors gave final approval and agreed to be accountable for all aspects of the work.

\section{Author contributions}

M.S. contributed to the conception, design, data acquisition, analysis, and interpretation drafted and critically revised the manuscript; N.H. contributed to the conception, design, data acquisition, analysis, and interpretation and critically revised the manuscript; R.H. contributed to analysis and critically revised the manuscript; J.T. contributed to the conception and critically revised the manuscript; F.H. contributed to data acquisition, analysis and critically revised the manuscript. All authors reviewed the manuscript. 


\section{Competing interests}

The authors declare no competing interests.

\section{Additional information}

Supplementary Information The online version contains supplementary material available at https://doi.org/ 10.1038/s41598-021-95279-x.

Correspondence and requests for materials should be addressed to N.H.

Reprints and permissions information is available at www.nature.com/reprints.

Publisher's note Springer Nature remains neutral with regard to jurisdictional claims in published maps and institutional affiliations.

(c) (1) Open Access This article is licensed under a Creative Commons Attribution 4.0 International License, which permits use, sharing, adaptation, distribution and reproduction in any medium or format, as long as you give appropriate credit to the original author(s) and the source, provide a link to the Creative Commons licence, and indicate if changes were made. The images or other third party material in this article are included in the article's Creative Commons licence, unless indicated otherwise in a credit line to the material. If material is not included in the article's Creative Commons licence and your intended use is not permitted by statutory regulation or exceeds the permitted use, you will need to obtain permission directly from the copyright holder. To view a copy of this licence, visit http://creativecommons.org/licenses/by/4.0/.

(C) The Author(s) 2021 